\title{
KONSEP PENDIDIKAN ISLAM DALAM Q.S. LUQMAN 12-19
}

\author{
Oleh: \\ Nurhayati \\ Fakultas Ushuluddin, Filsafat \& Politik \\ UIN Alauddin Makassar
}

\begin{abstract}
Abstrak
Pendidikan adalah usaha sadar untuk membina pribadi muslim yang memiliki akidah yang kuat, taat beribadah, memiliki kepekaan sosial serta tampil sebagai pribadi yang berakhlak mulia. Al-Qur'an mengabadikan Luqman sebagai sosok pribadi yang diberikan hikmah oleh Allah swt., bahkan al-Qur'an menunjukkan peran yang dimainkan oleh Luqman khususnya dalam pembinaan anak agar tumbuh dan berkembang sebagai pribadi yang berakhlak mulia. Dalam upayanya menanamkan ajaran Islam serta petunjuk pelaksanaan dari aspek kognitif, apektif dan psikomotorik, selalu dilakukan dengan penuh cinta dan kasih sayang, jauh dari kekerasan dan pemaksaan. Karena itu sosok Luqman yang diabadikan alQur'an, tetap relevan untuk pembinaan generasi muda Islam dewasa ini.
\end{abstract}

\section{Keywords:}

Luqman, al-Hakim, Syukur, Tauhid, Syirik, Shalat, Amar Makruf, Nahi Mungkar, Akhlak.

\section{PENDAHULUAN}

Al-Qur'an sebagai kitab hidayah bagi umat Islam, bukan hanya berisi pedoman dalam menjalani kehidupan di bumi ini tetapi juga berisi metode dan tatacara mengajarkan isi dari petunjuk tersebut agar bisa dipahami dengan baik.

Salah satu cara al-Qur'an menyampaikan petunjuknya kepada manusia adalah menyampaikannya dalam bentuk kisah yang menampilkan beragam tokoh dengan segala peran yang dimainkan pada masanya. Para tokoh yang ditampilkan al-Qur'an sangat beragam, tetapi semua yang ditampilkan kisahnya dalam alQur'an dimaksudkan agar umat Islam mengambil pelajaran dan menyesuaikannya dengan kehidupan mereka di manapun mereka berada.

Salah satu tokoh yang diabadikan namanya dalam al-Qur'an adalah Luqman, namanya diabadikan sebagai salah satu surah dalam al-Qur'an, yang memberikan petunjuk bahwa sosok Luqman adalah tokoh penting dalam sejarah kemanusiaan, khususnya dalam bidang pendidikan. Ketokohan Luqman seperti yang diabadikan al-Qur'an, bukan hanya pada materi pendidikan yang diajarkannya, yang selalu sesuai dengan situasi dan kondisi manusia dan masyarakat kapan dan di manapun, karena materi tersebut adalah materi yang universal, tetapi juga karena ketokohan Luqman yang sangat santun dalam menghadapi anaknya.

Tentu saja materi dan metode yang digunakan Luqman dalam mendidik, juga patut menjadi ibrah dan teladan bagi tenaga pendidik dalam mewujudkan generasi yang cerdas intelektual, cerdas sosial, emosional dan spiritual. 
Artikel ini secara singkat mengungkap konsep pendidikan yang disampaikan oleh Luqman dalam surah Luqman ayat 12-19 dengan fokus pada aspek materi dan metodenya.

\section{ASPEK-ASPEK PENDIDIKAN ISLAM DALAM Q.S. LUQMAN 12-19 \\ A. Figur Luqman Sebagai Tokoh Pendidik}

Sebelum membahas proses pendidikan yang dilakukan oleh Luqman terhadap anaknya, maka dikenalkan sosok tokoh tersebut. Ada beberapa pendapat mengenai sosok Luqman yang namanya diabadikan dalam salah surah surah dalam al-Qur'am, yaitu surah Luqman.

Nama Luqman disebut dalam Al-Qur'an dalam surah Luqman/31: 12-13. Ibnu Katsir berpendapat bahwa nama panjang Luqman ialah Luqman bin Unaqa' bin Sadun menurut kisah yang dikemukakan oleh As-Suhaili. ${ }^{1}$

Ulama berbeda pendapat mengenai sosok Luqman, tetapi al-Qur'an secara jelas menyatakan bahwa Luqman adalah orang yang diberikan hikmah oleh Allah swt. Menurut Ibnu Abbas, Luqman adalah seorang hamba berkebangsaan Habsyi (Ethiopia) yang berprofesi sebagai tukang kayu. Sementara Jabir bin Abdillah mengidentifikasi Luqman sebagai orang bertubuh pendek dan berhidung pesek. Sedangkan Said bin Musayyab mengatakan bahwa Luqman berasal dari kota Sudan, Memiliki kekuatan, dan mendapat hikmah dari Allah, namun dia tidak menerima kenabian. ${ }^{2}$

Buya Hamka dalam Tafsir Al-Azhar menegaskan bahwa di dalam mencari intisari Al-Qur'an tidaklah penting bagi kita mengetahui dari mana asal-usul Luqman. Al-Qur'an pun tidaklah menonjolkan asal-usul. Yang penting adalah dasar-dasar hikmah yang diwasiatkanya kepada puteranya yang mendapat kemulian demikian tinggi. Sampai dicatat menjadi ayat-ayat dari al-Qur'an, disebutkan namanya 2 kali, yaitu pada ayat 12 dan 13 dalam surah Luqman, yang diberi nama dengan nama Luqman. ${ }^{3}$

Dari penjelasan terseut dapat dinyatakan bahwa Luqman adalah seorang ahli hikmah, karena yang diajarkan kepada anaknya adalah hikmah yang telah dianugerahkan Allah swt. kepadanya.

Banyak sekali perkataan Luqman yang mengandung hikmah yang sangat berpengaruh dan tetap relevan dalam kehidupan manusia. Di antara perkataanya itu antara lain:

1. Jika kamu sedang sholat, maka jagalah hatimu, jika kamu sedang makan maka jagalah tenggorokanmu, jika kamu di rumah orang lain, maka jagalah pandanganmu, dan jika kamu berada di antara manusia maka jagalah lisanmu.

2. Ingatlah dua hal dan lupkan dua hal: adapun dua hal yang perlu kamu ingat adalah Allah swt. dan kematian, sedangkan dua hal yang perlu kamu lupakan adalah kebaikanmu kepada orang lain dan kejelekan orang lain terhadapmu. ${ }^{4}$

\footnotetext{
${ }^{1}$ M. Nasib Ar-Rifai, Kemudahan dari Allah: Ringkasan Tafsir Ibnu Katsir, (Jakarta : Gema Insani Press, 1999), h. 798

${ }^{2}$ Ibid.

${ }^{3}$ DHamka, Tafsir Al-Azhar, Juz XXI, (Jakarta : Pustaka Panji Mas, 1988), h. 114

${ }^{4}$ M. Ali Ash-Shabuny, Cahaya Al-Qur'an (Jakarta : Pustaka Al-Kautsar, 2002), h. 388
} 
3. Janganlah kamu bersandar dan cinta kepada dunia. Pandanglah dunia sebagai sebuah jembatan.

4. Janganlah memandangi apa yang ada di tangan orang (milik orang lain) dan bersikaplah dengan akhlak yang baik terhadap semua orang.

5. Kerjakanlah sholat di awal waktu dan tunaikanlah sholat berjamaah walau berada dalam kondisi tersulit.

6. Berusahalah menghindarkan dirimu dari bakaran api neraka selama engkau belum yakin akan selamat darinya.

7. Jika engkau mendurhakai Allah, maka carilah tempat sehingga engkau tidak dilihat oleh Allah dan malaikat-Nya. ${ }^{5}$

Ungkapan-ungkapan singkat tersebut di atas mengandung makna dan hikmah yang sangat mendalam, dan sangat penting dalam melaksanakan tugas di bumi ini serta menjaga dan memelihara hubungan dengan Allah swt. serta sesama manusia.

\section{B. Nilai-nilai Pendidikan dalam Q.S. Luqman/31: 12-19}

Ayat ke-12 Q.S. Luqman / $31: 12$

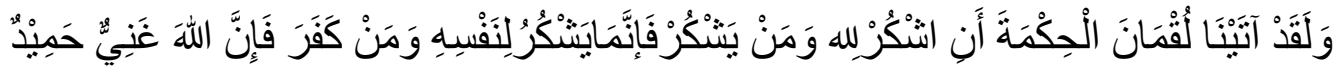

Terjemahnya:

Dan sesungguhnya telah kami berikan hikmah kepada Luqman, yaitu : Bersyukurlah kepada Allah, dan barang siapa yang bersyukur (kepada Allah), maka sesungguhnya ia bersukur untuk dirinya sendiri, dan barang siapa yang tidak bersyukur (kufur), maka sesungguhnya Allah Maha Kaya lagi Maha Terpuji. ${ }^{6}$

Dalam ayat 12 di atas diterangkan bahwa Allah telah memberikan hikmah, akal,paham dan memberikan petunjuk untuk memperoleh ma'rifat yang benar kepada Luqman. Oleh karena itu, Luqman menjadi seorang yang hakim (mempunyai hikmah). Ini memberikan pengertian bahwa ajaran Luqman yang disampaikan kepada anaknya berupa ajaran-ajaran hikmah. Orang yang mensyukuri nikmat Allah, sebenarnya dia bersyukur untuk kepentingan dirinya sendiri, sebab Allah akan memberikan pahala yang banyak dan melepaskan dari siksa. $^{7}$

Ayat ini menjelaskan bahwa perintah Allah swt. kepada Luqman untuk bersyukur kepada-Nya dengan beribadah kepada-Nya, menaati segala perintahNya dan menjauhi segala larangan-Nya seperti yang dilakukan oleh Luqman dengan berbagai kepribadian yang dimilikinya. Dengan bersyukur kepada Allah swt., maka manfaat itu akan kembali kepada pelakunya sebagai hamba. Akan tetapi bagi orang yang ingkar (tidak bersyukur) atas segala nikmat yang diberikan h. $39-41$

${ }^{5}$ Mohsen Qaraati, Seri Tafsir Untuk Anak Muda: Surah Luqman, (Jakarta: Al-Huda, 2005),

${ }^{6}$ Bachtiar Surin, Az-Zikra Terjemah dan Tafsir Al-Qur'an, Jilid 5 (Bandung: Angkasa, 2002), h. 1734

${ }^{7}$ M. Abdul Ghofar dan Abu Ihsan Al-Atsari, Tafsir Ibnu Katsir, Terj. Lubaabut Tafsir Min Ibni Katsiir, (Jakarta: Pustaka Imam Asy-Syafii, 2008), h. 3260 
Allah swt, maka dia (orang yang ingkar) tersebut akan mendapatkan balasan setimpal. Adapun Allah SWT sebagai Tuhan Yang Maha Kaya lagi Maha Terpuji tidak membutuhkan hamba dan Dia (Allah swt) tidak mendapat mudarat (kesengsaraan) jika seluruh penduduk bumi ingkar akan nikmat yang diberikanNya kepada seluruh makhluk, sebab Dia (Allah swt) tidak membutuhkan apapun dari makhluk-Nya.

Ayat ke-13 Q.S. Luqman/31:13

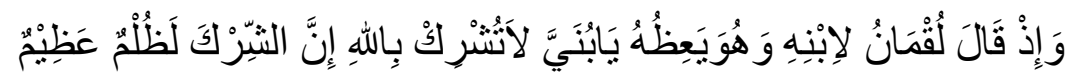

Terjemahnya:

Dan ingatlah ketika lukman berkata kepada anaknya di waktu ia memberi pelajaran kepadanya: Hai anakku, janganlah kamu mempersekutukan Allah, sesungguhnya mempersekutukan Allah adalah benar-benar kezaliman yang besar. $^{8}$

Pada ayat 13 ada kata ya'izhuhu (يعظه) yang terambil dari kata wa'zd(و عظه) yaitu nasihat menyangkut berbagai kebajikan dengan cara yang menyentuh hati. Luqman memulai nasihatnya dengan seruan menghindari syirik sekaligus mengandung pengajaran tentang wujud Allah yang Esa. ${ }^{9}$

Karena itu, dalam mendidik anaknya, Luqman menempuh cara yang amat baik, yang bisa meluluhkan hati anaknya sehingga mau mengikuti nasihat-nasihat yang diberikan.

Allah menjelaskan bahwa Luqman telah diberi hikmat, karena itu Luqman bersyukur kepada Tuhannya atas semua nikmat yang telah dilimpahkannya kepada dirinya.Allah SWT mewasiatkan kepada mereka supaya memperlakukanorangorang tua mereka dengan cara yang baik dan selalu memelihara hak-haknya sebagai orang tua. Luqman menjelaskan kepada anaknya, bahwa perbuatan syirik itu merupakan kezaliman yang besar.

Dalam ayat ke-13, disebutkan bahwa syirik (mempersekutukan Allah swt. merupakan benar-benar kezaliman yang besar. Karena itulah, mengapa Luqman memberikan pelajaran kepada anak akan pentingnya meninggalkan syirik. Untuk memperdalam tentang mengapa syirik merupakan kezaliman yang sangat besar, penulis akan mendeskripsikan sebagai berikut:

Adapun secara istilah, Mubarak mengutip pendapat al-Asfahâni mengatakan bahwa syirik secara istilah sama dengan kafir. ${ }^{10}$ Secara lebih rinci, syirik merupakan menjadikan tandingan selain Allah swt. dalam sifat rububiyahNya, uluhiyah-Nya, serta dalam nama-namanya dan sifat-sifatnya yang secara umum ialah menjadikan tandingan selain Allah SWT dalam uluhiyahnya dengan

\footnotetext{
${ }^{8}$ Bachtiar Surin, Az-Zikra Terjemah dan Tafsir Al-Qur'an, (Bandung : Angkasa, 2002).Jilid 5. h. 1734

${ }^{9}$ M. Quraish Shihab, Tafsir Al-Mishbah, Pesan, Kesan dan Keserasian Al-Qur'an,(Jakarta: Lentera Hati, 2002), h. 127

${ }^{10}$ Ibid., h. 103.
} 
berdoa atau memohon sesuatu kepada selain Allah atau mengganti selain Allah SWT dalam beribadah. ${ }^{11}$

Menurut Ibnu Katsîr dalam kitab Tafsîr Ibnu Katsîr disebutkan bahwa pertama-tama Luqman berpesan agar anaknya menyembah kepada Allah SWT yang Maha Esa, tiada sekutu baginya. Kemudian dia (Luqman) mewanti-wanti anaknya bahwa sesungguhnya mempersekutukan Allah Swt itu benar-benar kezaliman yang besar. ${ }^{12}$ Mengenalkan Allah swt. merupakan bagian yang paling dasar dari ajaran agama Islam yang harus dilakukan sebelum seseorang memberi pelajaran bagian dari ajaran Islam yang lain.

Ayat ke-14 Q.S. Luqman / $31: 14$

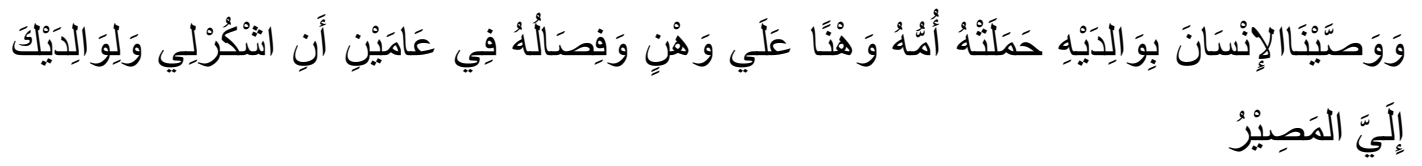

Terjemahnya:

Dan kami perintahkan kepada manusia (berbuat baik) kepada dua ibu bapaknya, ibunya telah mengandungya dalam keadaan lemah bertambahtambah, dan menyapihnya dalam dalam usia dua tahun. Bersyukurlah kepadaku dan kepada kedua ibu bapakmu, hanya kepadakulah kembalimu. ${ }^{13}$

Dalam ayat 14 ini, digambarkan bagaimana payah ibu mengandung, payah bertambah payah. Payah sejak dari mengandung bulan pertama, bertambah payah tiap bertambah bulan dan sampai di puncak kepayahan di waktu anak dilahirkan.Lemah sekujur badan ketika menghajan anak keluar, kemudia mengasuh,menyusui, memomong, menjaga, memelihara sakit senangnya. Dalam ujungayat ini, dianjurkan untuk bersyukur, syukur yang pertama ialah kepada Allah. Karena semua itu berkat rahmat Allah belaka. Setelah itu bersyukurlah kepada kedua orang tuamu, ibu yang mengasuh dan ayah yang membela dan melindungiibu dan melindungi anak-anaknya, ayah yang berusaha mencari sandang dan pangan setiap hari. ${ }^{14}$

Menurut Salman bin Fahad Al-Audah bahwa hak anak atas orang tua adalah denganmendidiknya ilmu agama yang mana salah satunya adalah tentang berbakti kepada orang tua. Karena kebanyakan orang tua lalai terhadap perhatian pendidikan anak dengan kesibukan seperti berdagang, kantor, sawah dan lain sebagainya. Sehingga ketika anak itu telah dewasa dan menjadi tidak sopan kepada orang tua, orang tua barulah kebingungan dengan anaknya yang membengkang

\footnotetext{
${ }^{11}$ Tim Penulis Gontor, Al-Tauhid, (Juz 3. Ponorogo: Darussalam Press), T.th, h. 10

${ }^{12}$ Al-Imam Al-Jalîl Al-Hafî̀dz Imad Al-Dîn abu Al-Fidâ' Ismaîl Ibnu Al-Dimasyqi Katsîr, Tafsîr al-Qur'an al- 'Azhîm, h. 53.

${ }^{13}$ Bachtiar Surin, Az-Zikra Terjemah dan Tafsir Al-Qur'an, (Bandung: Angkasa, 2002).Jilid 5. h. 1734

${ }^{14}$ Hamka, Tafsir Al-Azhar, ( Jakarta: P.T. Pustaka Panjimas, 1998), h. 129
} 
terhadap orang tua, barulah orang tua sadar akan pentingnya pendidikan akan agama terutama berbakti kepada orang tua. ${ }^{15}$

Ibu-bapak dalam ayat ini disebut secara umum, tidak dibedakan antara ibubapak yang muslim dengan yang kafir. Oleh Karena itu, dapat dipahami bahwa anak wajib berbuat baik kepada ibu bapaknya, apakah ibu bapaknya itu muslim atau kafir, jadi pada ayat yang ke-15 ini menerangkan bahwa dalam hal tertentu, seorang anak dilarang menaati ibu bapaknya jika mereka memerintahkannya untuk menyukutukan Allah, yang dia sendiri memang tidak mengetahui bahwaAllah mempunyai sekutu, karena memang tidak ada sekutu bagi-Nya. Sepanjang pengetahuan manusia, Allah tidak mempunyai sekutu. Karena menurut naluri,manusia harus mengesakan Tuhan. ${ }^{16}$

Ayat ke-15 Q.S. Luqman / 31 : 15
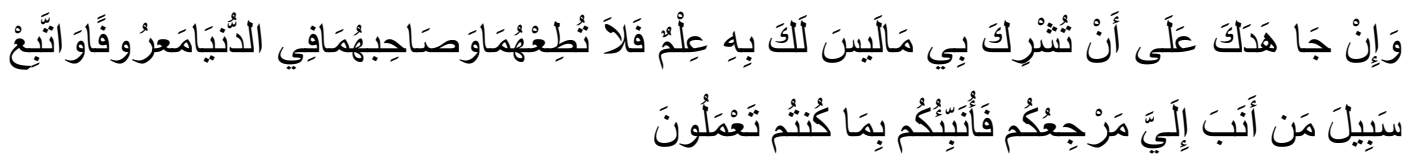

Terjemahnya:

Dan jika keduanya memaksamu untuk mempersekutukan aku dengan sesuatu yang engkau tidak mempunyai ilmu tentang itu, maka janganlah engkau mentaati keduanya, dan pergaulilah keduanya di dunia dengan baik, dan ikutilah jalan orang yang kembali kepadaku. Kemudian hanya kepadaku tempat kembalimu, maka akan aku beritahukan kepadamu apa yang telah kamu kerjakan. ${ }^{17}$

Dalam ayat ke-15 dari surah Luqman di atas, Allah swt. menyuruh kepada manusia untuk tetap berbakti kepada Allah swt. di dunia dengan baik, kecuali apabila mereka (kedua orang tua) menyuruh untuk menyalahi aturan Allah swt. maka wajib untuk menolaknya. Nilai ini sangat penting untuk diketahui anak. Selain anak mengetahui bahwa dia harus mempunyai akidah yang kuat, dia juga harus mengedapankan kebaikan kepada kedua orang tua selama dalam kebaikan.

Hal yang dilakukan oleh Luqman dalam mendidik anak yakni tentang menghormati orang tua selama masih di jalan Allah swt. dan memegang teguh akidah apabila orang tua menyuruh untuk berpaling di jalan Allah swt. bisa menjadi contoh bagi semua orang termasuk dalam dunia pendidikan. Ketika sang pendidik atau guru mengajarkan sesuatu yang bertentangan dengan aturan Allah SWT seperti disuruh mencontek,tidak jujur, dan lain sebagainya yang bertentangan dengan aturan agama, maka murid atau anak didik wajib dan harus menolaknya walaupun yang memerintah adalah guru. Karena perintah yang selalu harus ditaati adalah perintah yang sesuai dengan agama Islam atau sesuai dengan aturan Allah SWT yang pencipta alam semesta.

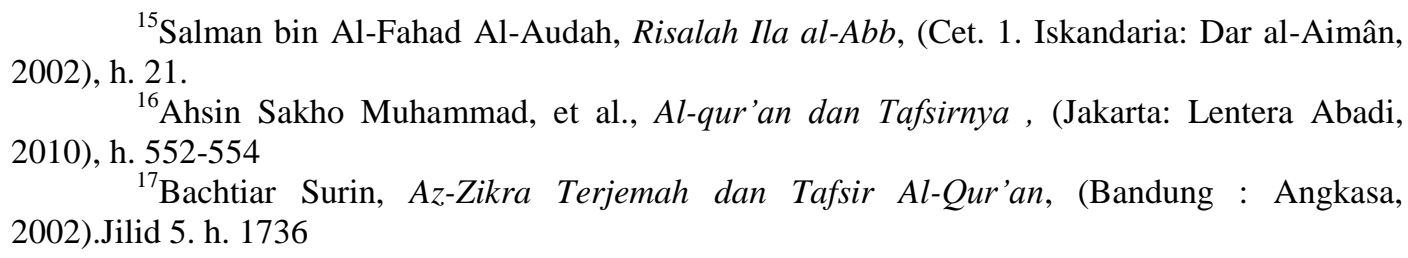

${ }^{15}$ Salman bin Al-Fahad Al-Audah, Risalah Ila al-Abb, (Cet. 1. Iskandaria: Dar al-Aimân,

${ }^{16}$ Ahsin Sakho Muhammad, et al., Al-qur'an dan Tafsirnya , (Jakarta: Lentera Abadi, 2010), h. 552-554

${ }^{17}$ Bachtiar Surin, Az-Zikra Terjemah dan Tafsir Al-Qur'an, (Bandung : Angkasa, 2002).Jilid 5. h. 1736 
Ayat ke-16 Q.S. Luqman / $31: 16$

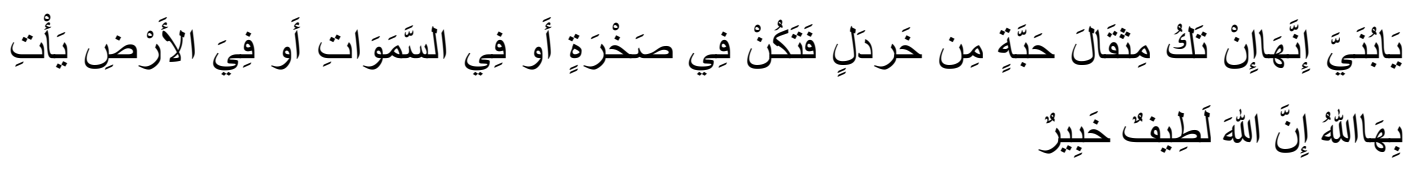

Terjemahnya:

(Lukman berkata), “Wahai Anakku! Sesungguhnya, jika ada (sesuatu perbuatan) seberat biji sawi, dan berada dalam batu atau di langit atau di bumi, niscaya Allah akan memberinya (balasan). Sesungguhnya Allah Maha Luas lagi Maha Mengetahui. ${ }^{18}$

Pada ayat 16 diatas Luqman melanjutkan wasiatnya dengan memberikan perumpamaan, yaitu walaupun perbuatan baik dan perbuatan buruk itu sekalipun beratnya hanya sebiji sawi dan berada di tempat yang tersembunyi, niscaya perbuatan itu akan dikemukakan oleh Allah SWT kelak di hari kiamat, yaitu pada hari ketika Allah meletakan timbangan amal perbuatan yang tepat, kemudian pelakunya akan menerima pembalasan amal perbuatannya, apabila amalnya itu baik maka balasannya akan baik pula dan apabila amalnya buruk maka balasannya pun akan buruk pula. ${ }^{19}$

Dengan demikian penanaman nilai ini akan menjadikan murid dapat mengambil peran untuk selalu berbuat baik demi dirinya agar mendapatkan keberhasilan di masa depan.

Ayat ke-17 Q.S. Luqman / $31: 17$

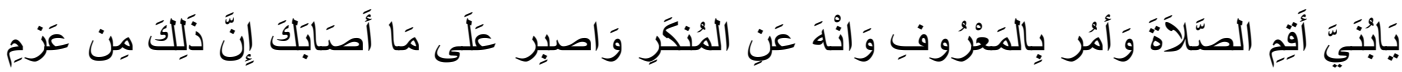
الأُمْور

Terjemahnya:

Hai anakku, dirikanlah shalat dan suruhlah (manusia) mengerjakan yang baik dan cegahlah (mereka) dari perbuatan yang mungkar dan bersabarlah terhadap apa yang menimpa kamu. Sesungguhnya yang demikian itu termasuk hal-hal yang diwajibkan (oleh Allah). ${ }^{20}$

Pada ayat 17 ini, Lukman mewasiatkan kepada anaknya hal-hal berikut :

1. Selalu mendirikan sholat dengan sebaik-baiknya, sehingga diridai Allah. Jika sholat yang dikerjakan itu diridai Allah, perbuatan keji dan perbuatan mungkardapat dicegah, jiwa menjadi bersih, tidak ada kekhawatiran terhadap diri orang itu, dan mereka tidak akan bersedih hati jika ditimpa cobaan, dan merasadirinya semakin dekat dengan Tuhannya.

\footnotetext{
${ }^{18}$ Bachtiar Surin, Az-Zikra Terjemah dan Tafsir Al-Qur'an, (Bandung : Angkasa, 2002).Jilid 5. h. 1736

${ }^{19}$ Ahmad Mustafa Al-Mustafa Al-Maragi, Tafsir Al-Maragi, (Semarang: Toha Putra, 1992), h. 157-158

${ }^{20}$ Bachtiar Surin, Az-Zikra Terjemah dan Tafsir Al-Qur'an, (Bandung : Angkasa, 2002).Jilid 5. h. 1737
} 
2. Berusaha mengajak manusia mengerjakan perbuatan-perbuatan baik yangdiridai Allah, berusaha membersihkan jiwa, dan mencapai keberuntungan, sertamencegah mereka agar tidak mengerjakan perbuatanperbuatan dosa.

3. Selalu bersabar dan tabah terhadap segala macam cobaan yang menimpa,akibat dari mengajak manusia berbuat baik dan meninggalkan perbuatan yang mungkar, baik cobaan itu dalam bentuk kesenangan dan kemegahan, maupundalam bentuk kesengsaraan dan penderitaan. ${ }^{21}$

Selain perintah shalat, nilai pendidikan selanjutnya adalah nasehat Luqman kepada anaknya tentang amar ma`ruf dan nahi mungkar. Untuk menjalankan amar ma'ruf dan nahi mungkar ini membutuhkan stamina yang kuat, sebab mengandung resiko yang besar. Oleh karena itu, Ibnu Katsir memberikan solusi yaitu sesuai dengan kesanggupan untuk bersabar terhadap apa yang menimpamanusia dalam upaya menyerukan agama Allah SWT. Sebab orang yang menyeru kepada jalan Allah pasti mendapat gangguan. Kesabaran dalam menghadapi gangguan manusia haruslah dimiliki oleh para penyeru agama Allah SWT. ${ }^{22}$

Perintah untuk menyuruh mengerjakan yang baik dan cegahlah dari perbuatan yang mungkar ini hendaklah diajarkan kepada anak dan murid seperti halnya yang dilakukan Luqman kepada anaknya. Karena dengan penanaman ini, murid akan mempunyai kekuatan diri yaitu rasa percaya diri untuk selalu berbuat baik kepada sesama teman dalam hal berbuat baik dan mengingatkan teman mereka apabila mereka berbuat yang tidak baik. Oleh karena itu peran orang tua dan pendidik (guru) hendaklah mengajarkan para murid untuk selalu berperan aktif dalam hal kebaikan ini baik di sekolah maupun di rumah atau di lingkungan masyarakat yang luas pada umumnya.

Ayat ke- 18 Q.S. Luqman / $31: 18$

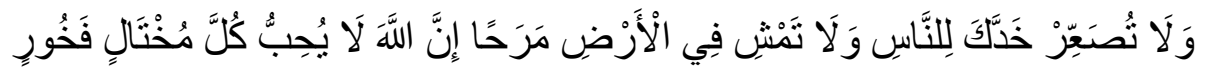

Terjemahnya:

Dan janganlah kaтu memalingkan mukamu dari manusia (karena sombong) dan janganlah kamu berjalan di muka bumi dengan angkuh. Sesungguhnya Allah tidak menyukai orang-orang yang sombong lagi membanggakan diri. ${ }^{23}$

Pada ayat 18 diatas, Luqman mengajarkan kepada anaknya agar janagna memalongkan muka dari manusia karena sombong dan berjalan dengan membusungkan dada, dan memalingkan muka dari manusia karena sombong dan merasa tinggi hati.

\footnotetext{
${ }^{21}$ Ahsin Sakho Muhammad, et al., Al-Qur'an dan Tafsirnya , (Jakarta: Lentera Abadi,2010), h. 555

${ }^{22}$ Al-Imam al-Jalîl al-Hafî̀dz Imad al-Dîn abu al-Fidâ' Ismaîl Ibnu al-Dimasyqi Katsîr, Tafsîr al-Qur'an al- 'Azhîm, h. 56.

${ }^{23}$ Bachtiar Surin, Az-Zikra Terjemah dan Tafsir Al-Qur'an, (Bandung: Angkasa, 2002).Jilid 5. h. 1737
} 
Oleh karena itu, hendaknya anak dididik dengan baik yaitu menanamkan nilai-nilai kebaikan di tengah masyarakat dan menjauhkan anak dari kemungkaran yang ada di tengah masyarakat seperti menghindarkan anak dari sifat sombong yang anak merugikan anak tersubut dalam hidup bermasyarakat. Karena manusia merupakan makhluk sosial yang membutuhkan orang lain dalam hidupnya, sehingga dengan menjauhkan anak dari sifat sombong, makaakan membuat anak menjadi lebih nyaman dalam hidup bermasyarakat. Dengan demikian, bagi para orang tua dan guru hendaklah memberikan nasehat kepada anak dan murid agar menjauhi berbuat sombong. Karena kesombongan anak merugikan diri anak pribadi sendiri. Oleh karena itu tidak pantas terbesit adanya rasa sombong dari dalam diri. Kesombongan hanya milik Allah SWT sang Maha Pencipta Alam.

Ayat ke-19Q.S. Luqman / $31: 19$

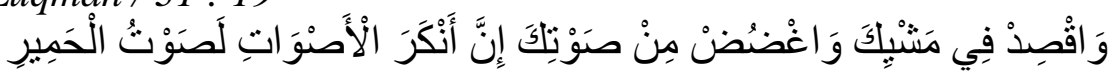

Terjemahnya:

Dan sederhanalah kamu dalam berjalan dan lunakkanlah suaramu. Sesungguhnya seburuk-buruk suara ialah suara keledai. ${ }^{24}$

Dalam menafasirkan ayat ke-19 ini, Ibnu Katsir mengutip pendapatnya Mujahid sebagai berikut:

Mujahid dan yang lain mengatakan: sesungguhnya seburuk-buruk suara ialah suara keledai. Yakni suara terburuk selain suara yang keras yang diserupakan dengan suara keledai dalam hal melengking dan kerasnya. Di samping buruk hal itu juga dimurkai Allah Swt. Penyerupaan suara keras dengan suara keledai menetapkan keharaman dan ketercelaannya, sebab Rasulullah Saw bersabda: Kami tidak memiliki perumpamaan terburuk, orang yang mengambil kembali harta yang dihibahkannya adalah seperti anjing muntah, lalu memakan kembali muntahannya. ${ }^{25}$

Dengan demikian, anjuran agar berjalan dengan tidak cepat dan tidak lambat serta anjuran agar berkata dengan baik yakni tidak keras merupakan upaya untuk mendidik anak agar sopan dalam berjalan dan berkata. Hal ini menjadi penting bagi para orang tua dan guru untuk menasehati seperti yang diungkapkan Luqman ini, agar anak menjadi sopan dalam berjalan dan berkata dalam kehidupan sehari-hari baik di rumah, sekolah maupun di masyarakat luas.

Pada ayat 19 diatas menjelaskan:

Pertama, tentang cara berjalandengan langkah yang sederhana, yakni tidak terlalu lambat dan juga tidak terlalu cepat, akan tetapi berjalanlah dengan wajar tanpa dibuat-buat dan juga tanpa pamer menonjolkan sikap rendah hati atau sikap tawadu.

Kedua, tentang caraberbicara yakni dengan mengurangi tingkat kekerasan suara, jangan mengangkat suara jika tidak diperlukan sekali. Karena sesungguhnya

\footnotetext{
${ }^{24}$ Bachtiar Surin, Az-Zikra Terjemah dan Tafsir Al-Qur'an, (Bandung: Angkasa, 2002).Jilid 5. h. 1734

${ }^{25}$ Al-Imam Al-Jalîl Al-Hafîdz Imad Al-Dîn abu Al-Fidâ’ Ismaîl Ibnu Al-Dimasyqi Katsîr, Tafsîr al-Qur'an al-'Azhîm, h. 58.
} 
sikap yang demikian itu lebih berwibawa bagi yang melakukannya, dan mudah diterima oleh jiwa pendengarnya serta lebih gampang untuk dimengerti.

Ketiga, tentang ilat atau alasan yang melarang hal diatas yakni sesungguhnya suara yang paling buruk dan paling jelek, karena ia dikeraskan lebih daripada apa yang diperlukan tanpa penyebab adalah suara keledai. Dengan kata lain, bahwa orang yang mengeraskan suaranya itu berarti suaranya mirip suara keledai. Dalam hal ini ketinggian nada dan kekerasan suara, dan suara yang seperti itu sangat dibenci oleh Allah swt.

Di dalam ungkapan ini jelas menunjukan nada celaka dan kecamanterhadap orang yang mngeraskan suaranya, serta anjuran untuk membenci perbuatan tersebut. Di dalam ungkapan ini yaitu menjadikan orang yang mengeraskan suaranya diserupakan dengan suara keledai, terkandung pengertian mubalagah untuk menanamkan rasa antipati dari perbuatan tersebut. Hal ini merupakan pendidikan dari Allah untuk hamba-hamba-nya supaya mereka tidak mengeraskan suaranya di hadapan orang-orang karena meremehkan mereka, atau yang dimaksud ialah agar mereka meninggalkan perbuatan ini secara menyeluruh (dalam kondisi apapun). ${ }^{26}$

Dengan demikian tuntunan menghindarkan diri dari ucapan dan perilaku tercela yang diajarkan Luqman kepada anaknya, dilakukan dengan cara yang sangat santun dan menyentuh hati.

\section{III.PENUTUP}

1. Luqman adalah sosok pribadi yang diberikan hikmah oleh Allah swt., karena itu namanya diabadikan sebagai salah satu nama surah dalam al-Qur'an untuk menunjukkan betapa besar peran yang dimainkan oleh Luqman khususnya dalam pembinaan anak agar tumbuh dan berkembang sebagai pribadi yang berakhlak mulia.

2. Luqman memberikan dasar pendidikan yang sangat kokoh berupa akidah tauhid sebagai landasan bangunan kehidupan seorang muslim. Pada sisi lain, Luqman mengingatkan kepada anaknya agar jangan merusak akidah tauhid dengan syirik, bahkan dijelaskan bahwa syirik adalah kezaliman yang teramat besar. Luqman juga menanamkan sikap hormat kepada kedua orang tua yang telah mengasuh, mendidik dan membimbing dengan penuh rasa tangung jawab dan kasih. Penempatan perintah berbuat baik kepada kedua orang tua, setelah perintah tauhid menunjukkan penting berbuat baik kepada kedua orang.

${ }^{26}$ Ahmad Mustafa Al-Mustafa Al-Maragi, Tafsir Al-Maragi, (Semarang: Toha Putra, 1992), h. 162-163 
3. Luqman menanamkan pelaksanaan ibadah mahdhah seperti shalat nserta pelaksanaan anamr makruf nahi mungkar dalam kehidupan bermasyarakat serta menghiasi diri dengan akhlak mulia dan menghindarkan diri dari akhlak tercela.

4. Semua materi pendidikan yang diajarkan Luqman kepada anaknya dilakukan dengan kesadaran akan kekuasaan Allah swt. serta dilakukan dengan penuh cinta dan kasih sayang, jauh dari kekerasan dan pemaksaan.

\section{DAFTAR PUSTAKA}

Al-Qur'an al-Karim

Ad-DamanhuriAhmad, Idohul Mubham, Semarang: Toha Putra.

Al-Audah bin Al-Fahad Salman, Risalah Ila al-Abb, Cet. 1. Iskandaria: Dar alAimân, 2002.

Al-Imam Al-Jalîl Al-Hafî̀dz Imad Al-Dîn abu Al-Fidâ' Ismaîl Ibnu Al-Dimasyqi Katsîr, Tafsîr al-Qur'an al- 'Azhîm.

Al-Maili bin Muhammad Mubârak,. Risalah al-Syirik wa Madhahirihi, (Cet. 1. Riyadh: Dar al-Râyah, 2001.

Alim Muhammad, Pendidikan Agama Islam Upaya Pembentukan Pemikiran dan Kepribadian Muslim, Bandung: PT Remaja Rosda Karya, 2006.

Al-Maraghi Ahmad Mustafa, Tafsir Al-Maraghi, Semarang: Toha Putra, 1992.

Hamka. Tafsir Al-Azhar Juz, 21, Jakarta : PT Pustaka Panjimas,2006.

Shihab, M. Quraisy, Tafsir Al-Mishbah,Pesan, Kesan dan Keserasian AlQur'an,Jakarta: Lentera Hati, 2002.

Sudirman. et al.Ilmu Pendidikan Islam, Bandung : Remaja Rosdakarya,1991.

Surin Bachtiar, Az-Zikra Terjemah dan Tafsir Al-Qur'an, Bandung : Angkasa, 2002.

Tatapangsara Humaidi, TIM Dosen Agama Islam, Pendidikan Agama Islam untuk Mahasiswa, Malang; Ikip Malang, 1990. 